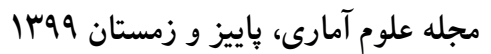

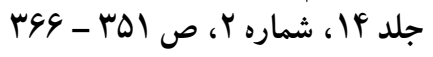

DOI: 10.29252/jss.14.2.351

بهينهسازى قابليت اطمينان و هزينه در سيستمهاى سرى-موازى تعميريذير با نرخ شكست وانىشكل

$$
\text { الهام بصيرى }
$$

كروه آمار، دانشكاه كوثر بجنورد

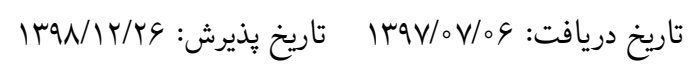

جكيده: وقتى يك سيستم مورد استفاده قرار مى إىيرد، تعيين قابليت اطمينان اين سيستم، يعنى احتمال

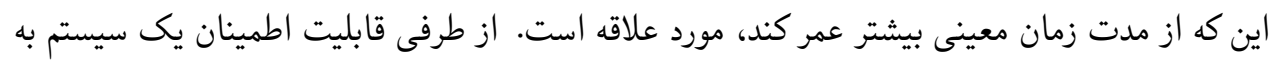

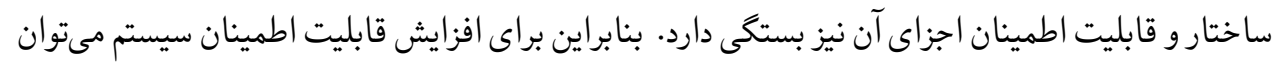

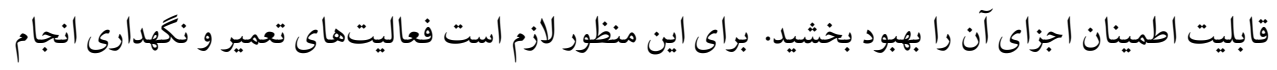

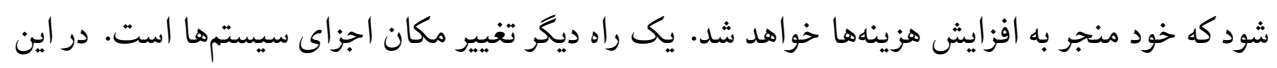

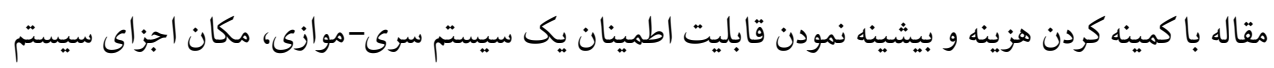

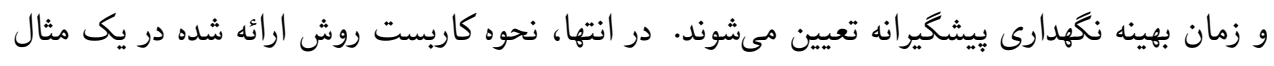
عددى نشان داده مىشود. وازههاى كليدى: سيستم سرى-موازى، تعمير و نكهدارى، نرخ شكست وانىشكل، بهينهازى، قابليت | اطمينان. 


\section{|}

در دنياى صنعتى رقابت در توليد محصولات و انتظارات مشتريان افزايش يافته و به دنبال آن توليدكندكان

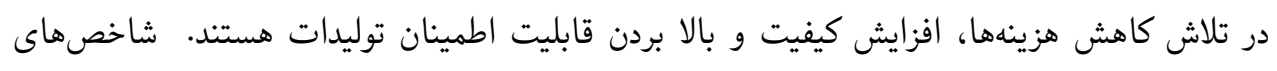

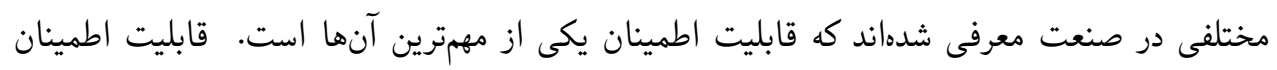

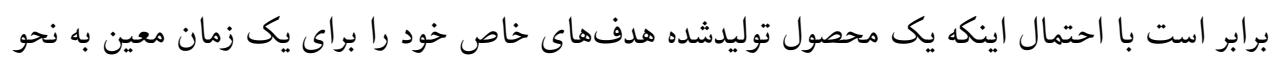

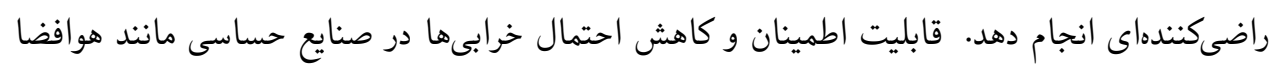

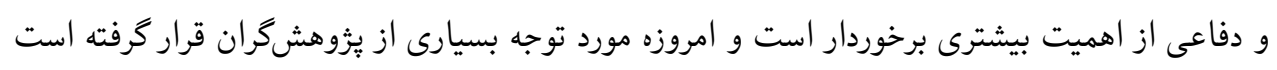

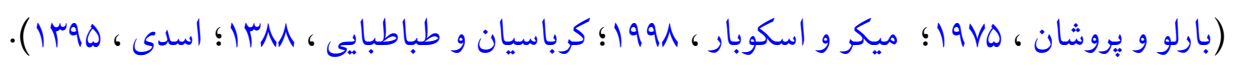

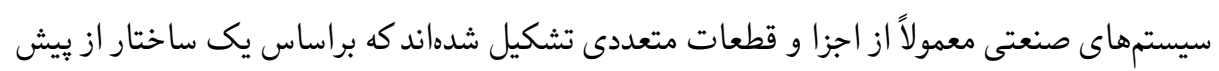

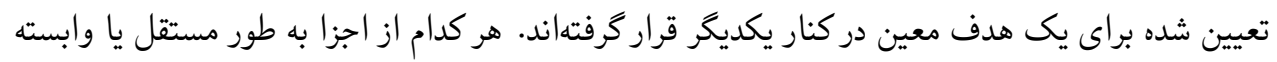

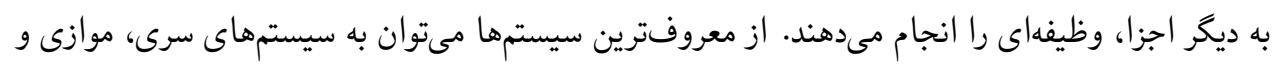

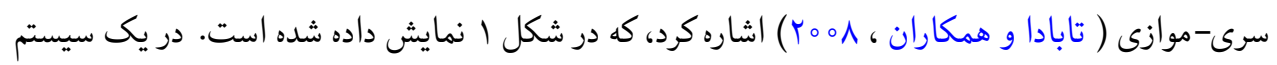

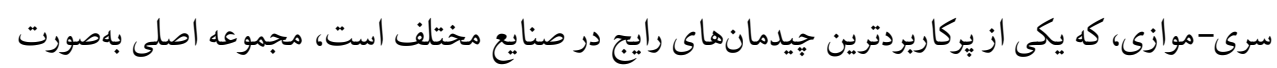

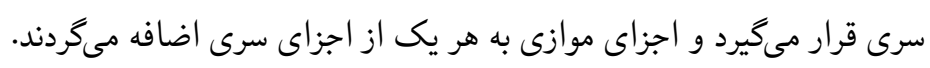

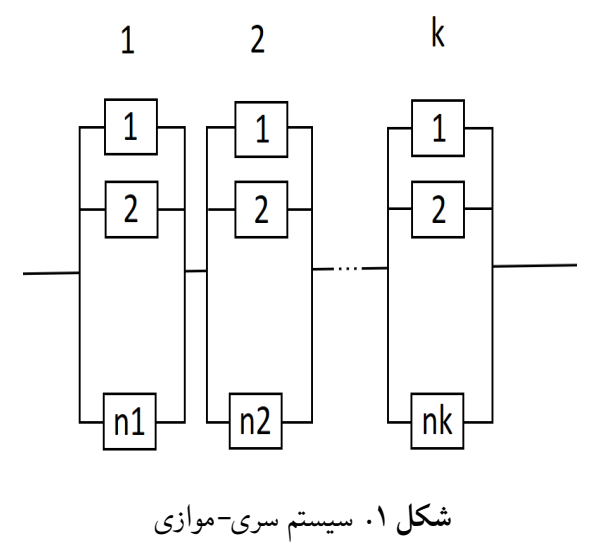

تابع قابليت اطمينان' يا تابع بقا' براى يك سيستم سرى-موازى متشكل از k سيستم سرى، هر يك

${ }^{1}$ Reliability Function

${ }^{2}$ Survival Function 


$$
R_{\text {sys }}(t)=\prod_{i=1}^{k}\left(1-\prod_{j=1}^{n_{i}}\left(1-R_{i j}(t)\right)\right)
$$

$$
\text { است، كه در آن Rij قابليت اطمينان جزء زام در زيرسيستم أم است. }
$$

يكى از موضوعات مهم در نظريه قابليت اطمينان مبحث تعمير و نكهدارى' است. تقريباً تمام سيستهها

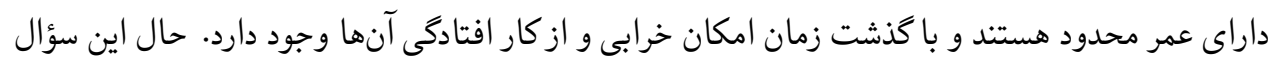

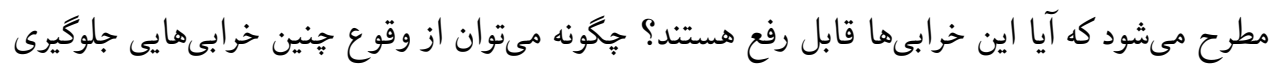

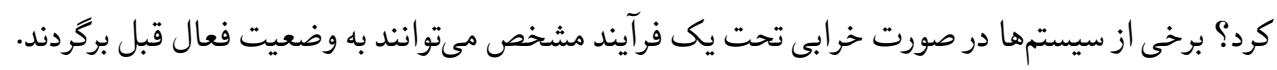

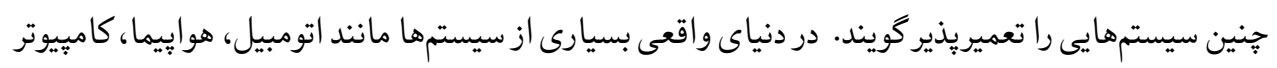

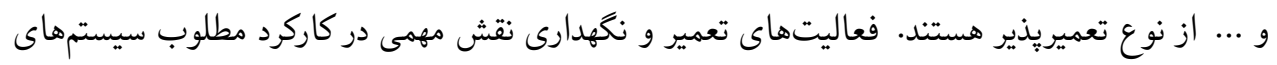

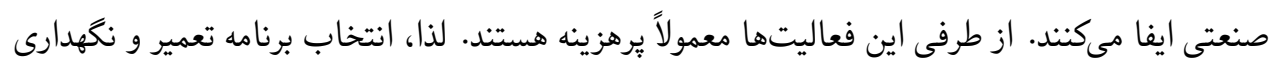

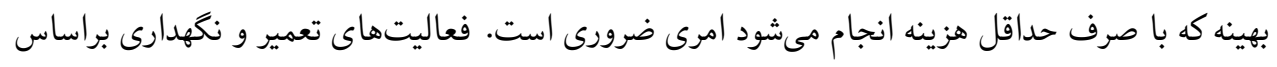

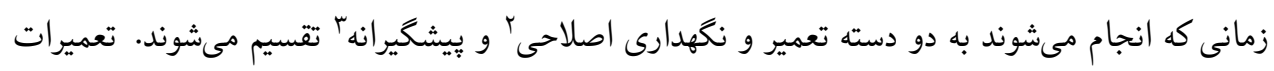

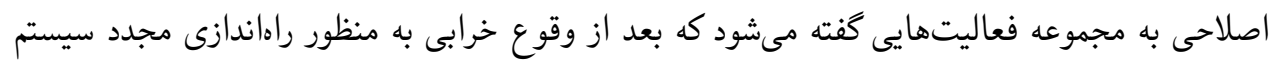

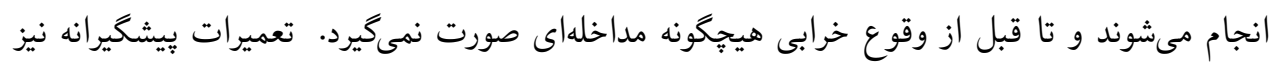

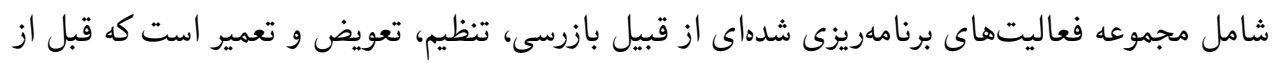

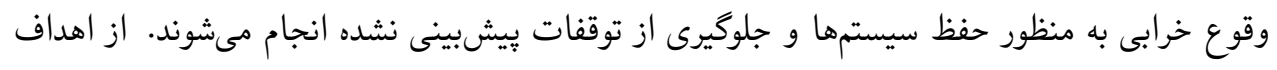

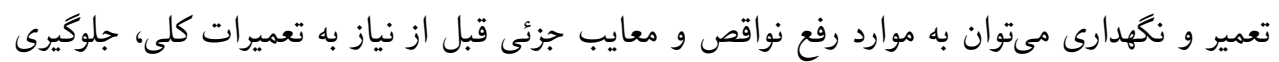

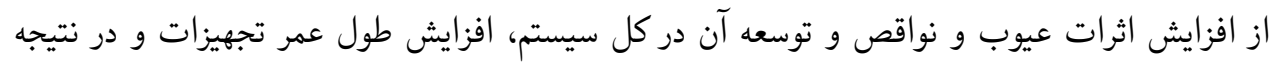

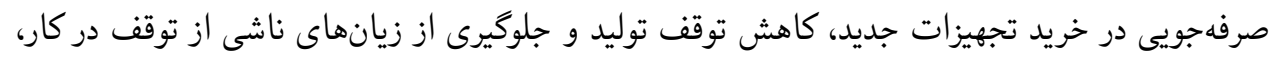

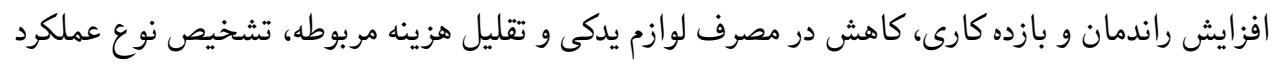

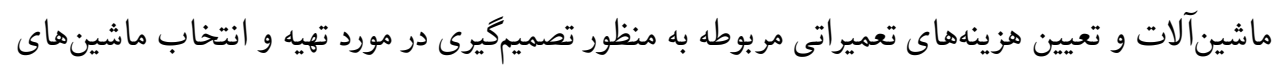

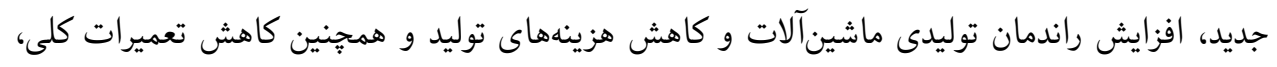

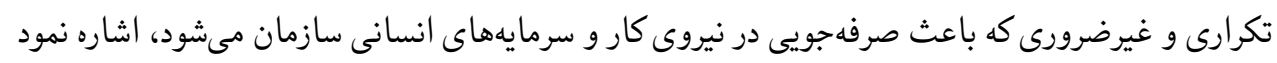

\footnotetext{
${ }^{1}$ Maintenance

${ }^{2}$ Corrective Maintenance

${ }^{3}$ Preventive Maintenance
} 
. بهينهازى قابليت اطمينان و هزينه در سيستمهاى سرى-موازى

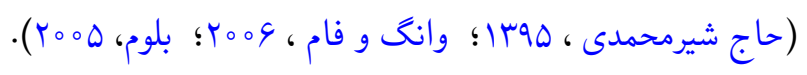

تابع نرخ شكست' نشاندهنده عملكرد شكست در طول زمان است. اين كميت در واقع نرخ از كارافتادكى سيستم را در زمان t نمايش مىدهد و معيارى براى اندازهيرى سالخوردكى سيستم است.

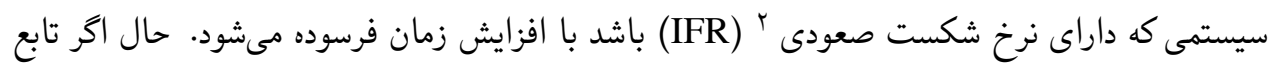

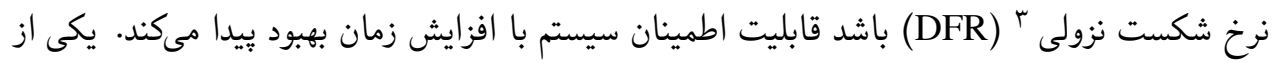

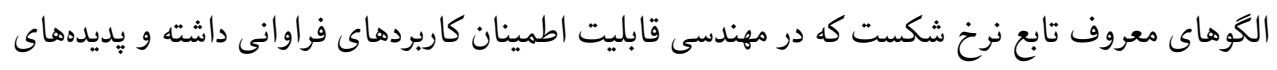

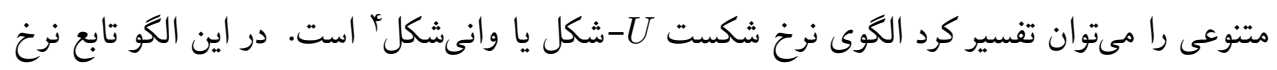

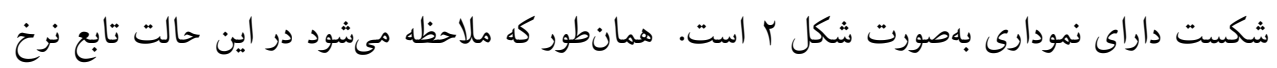

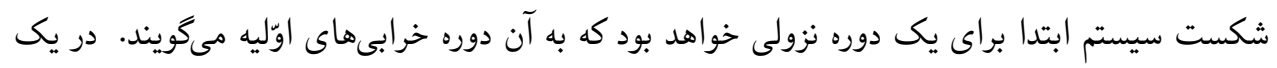

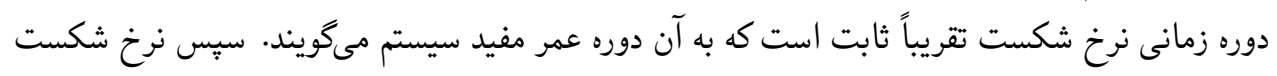

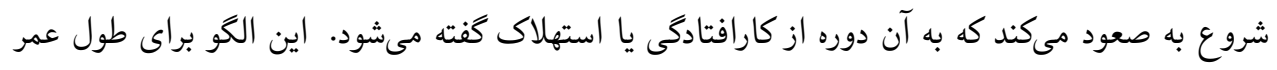

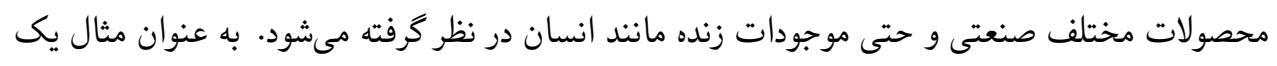

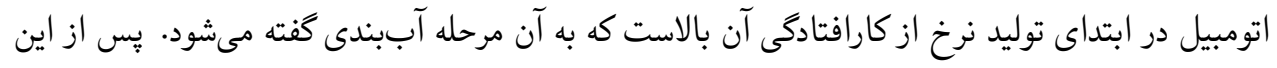

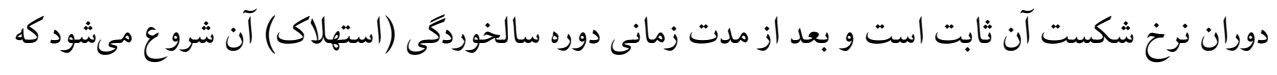

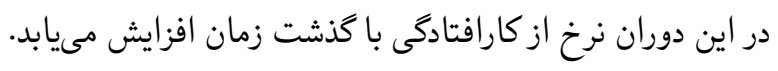

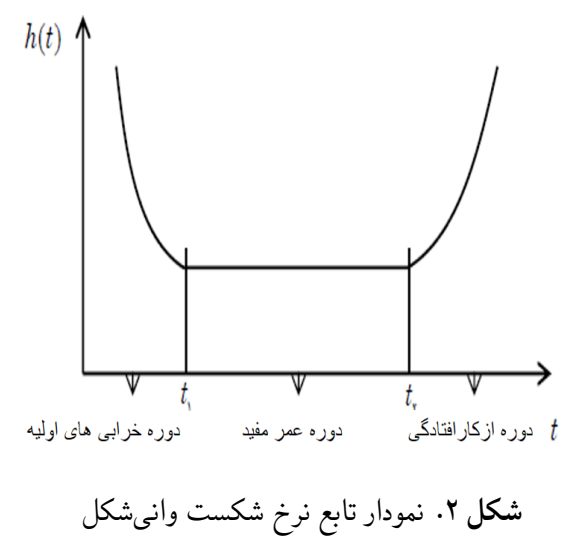

${ }^{1}$ Failure Rate Function

${ }^{2}$ Increasing Failure Rate

${ }^{3}$ Decreasing Failure Rate

${ }^{4}$ Bathtub-Shaped 
يكى از توزيعهاى مهم طول عمر توزيع وايبل' است، كه به دليل انعطافيذيرى بالا در مطالعات قابليت

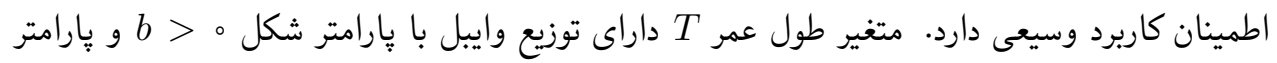

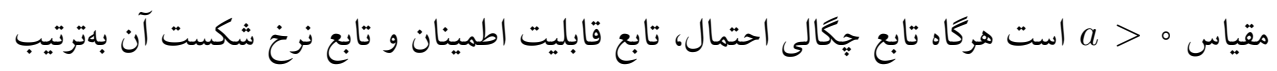
بهصورت

$$
\begin{aligned}
f(t) & =b a^{b} t^{b-1} e^{-(a t)^{b}}, \quad t>0 \\
R(t) & =e^{-(a t)^{b}} \\
h(t) & =b a^{b} t^{b-1} .
\end{aligned}
$$

باشند. يكى از مهّمترين دلايل شهرت اين توزيع اين است كه با تغيير بارامترها، تابع نرخ شكست اين

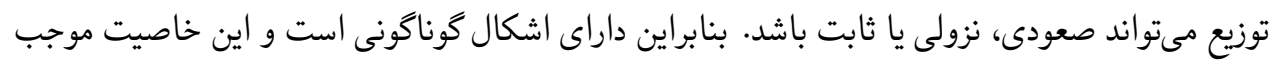

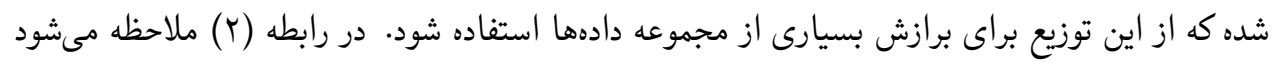

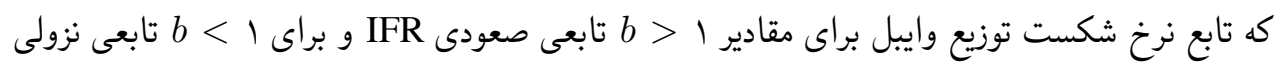

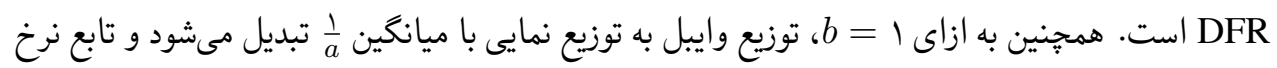

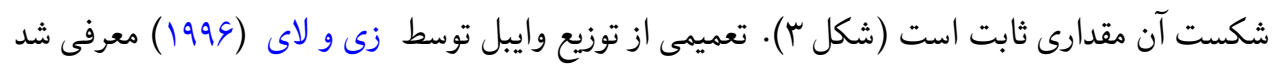

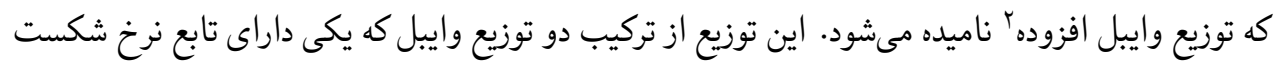

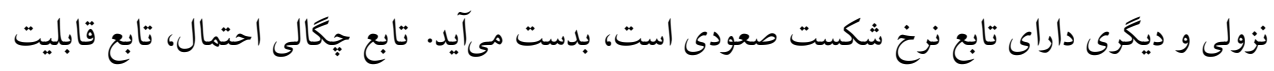

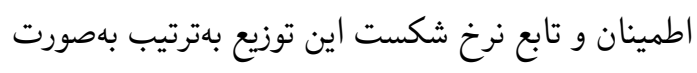

$$
\begin{aligned}
f(t) & =\left(b a^{b} t^{b-1}+d c^{d} t^{d-1}\right) e^{-(a t)^{b}-(c t)^{d}}, \quad t>\circ, b>1, d<1, a, c>\circ, \\
R(t) & =e^{-(a t)^{b}-(c t)^{d}} \\
h(t) & =b a^{b} t^{b-1}+d c^{d} t^{d-1}
\end{aligned}
$$

هستند. با مشتقگيرى از تابع نرخ شكست (Y) و مساوى صفر قرار دادن آن مىتوان نشان داد كه تابع 


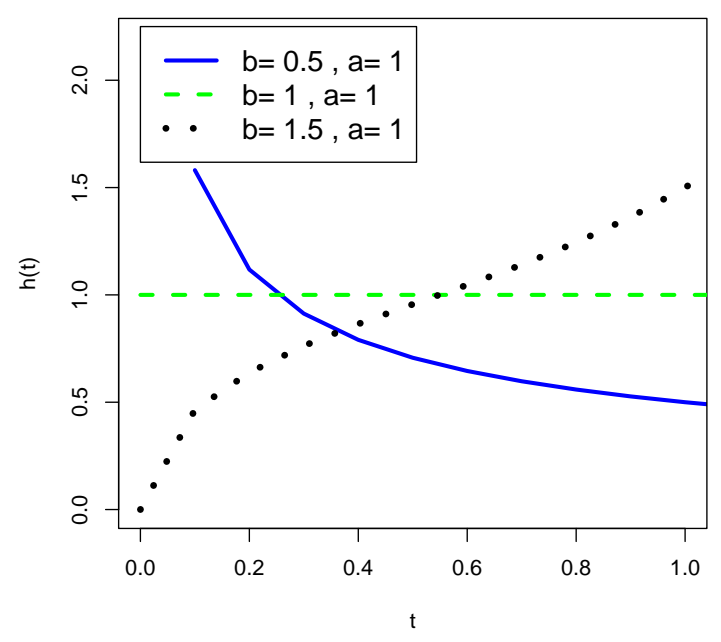

$$
\text { شكل r. نمودار تابع نرخ شكست توزيع وايبل }
$$

نرخ شكست در زمان 。t به حداقل مقدار خود مىرسد و سيس افزايش مىيابد، هركاه

$$
t_{\circ}=\left(\frac{d(1-d) c^{d}}{b(b-1) a^{b}}\right)^{\frac{1}{b-d}}
$$

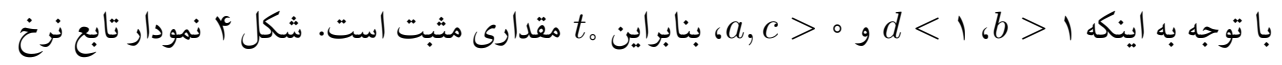

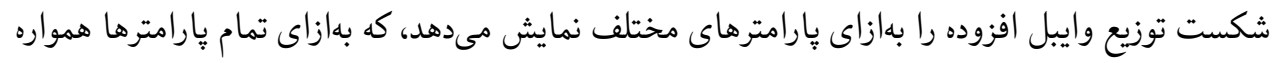
وانىشكل است. مسأله مرتبط با سيستها از منظرهاى مختلفى مورد مطالعه قرار كرفته است. آشر و فينگلد ( 19 (19Y)

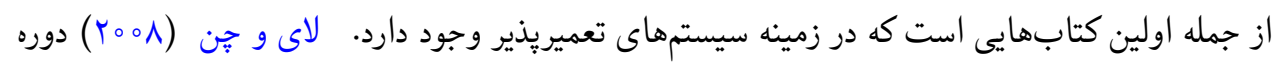

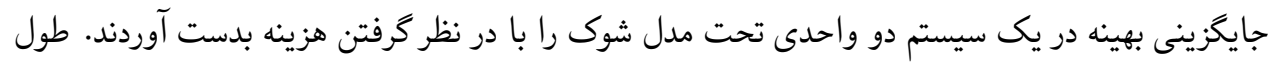

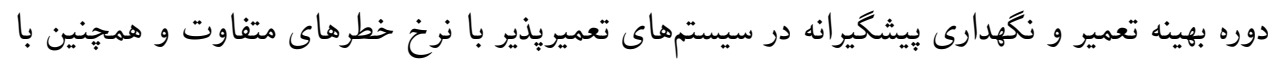

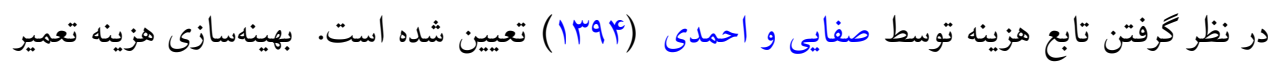

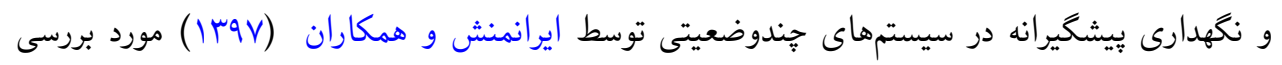

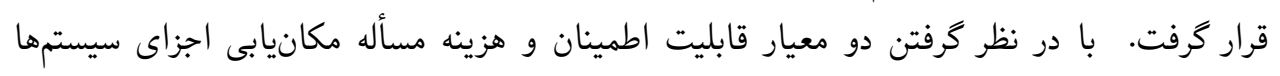




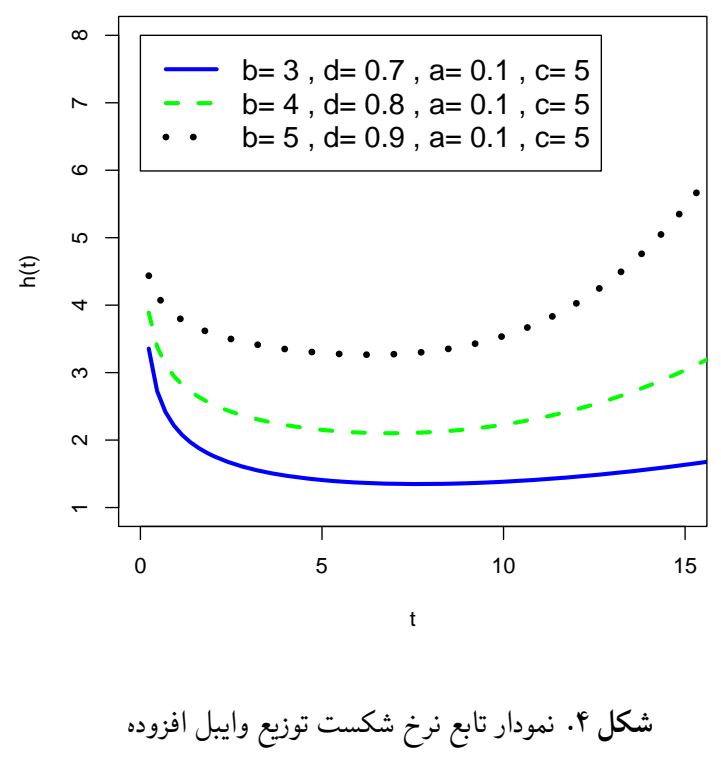

توسط كرباسيان و همكاران (1/99) براى سيستهاى سرى با طول عمر وايبل با پارامتر شكل بزركتر

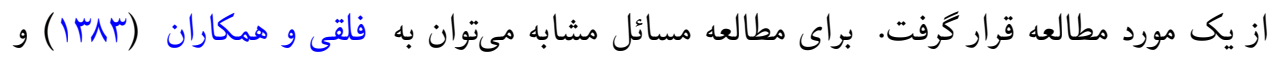

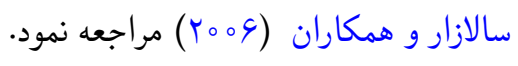

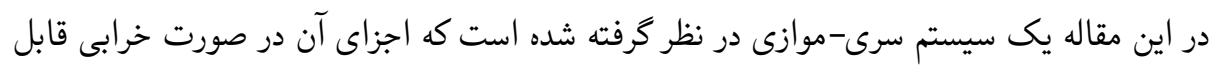

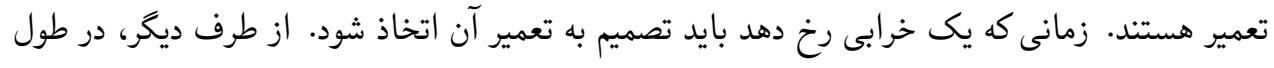

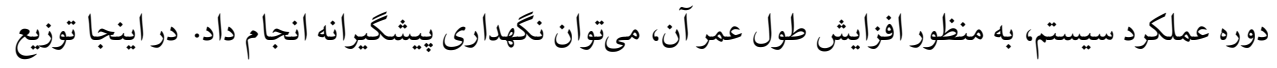

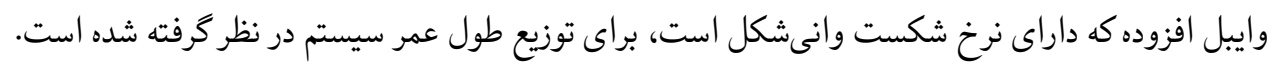

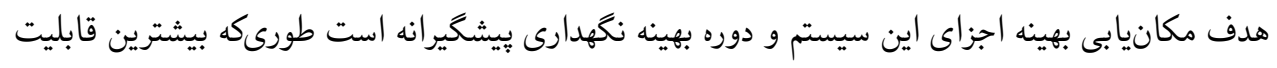

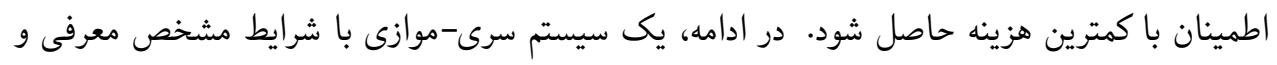

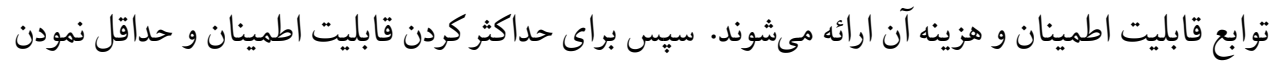

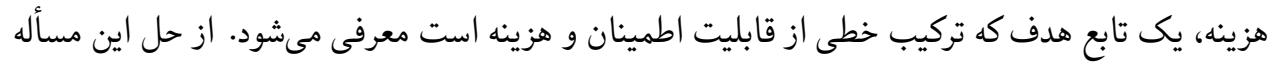

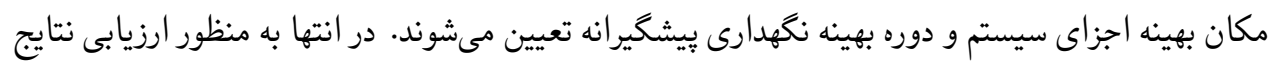
مقاله به ارائه يك مثال يرداخته شده است. 
بعينهسازى قابليت اطمينان و هزينه در سيستهاى سرى-موازى

\section{ب ب بان مسأله}

سيستمى سرى-موازى كه متشكل از k سيستم سرى با in، k >

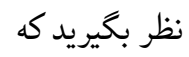
الف - همه اجزاى سيستم تعميريذير باشند.

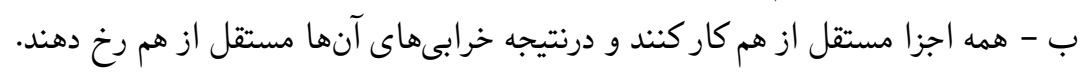

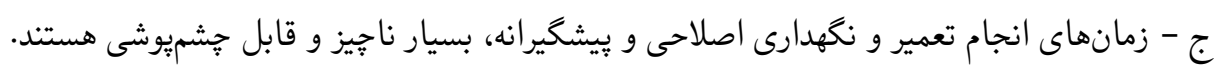

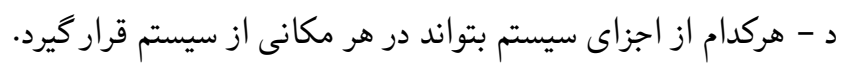

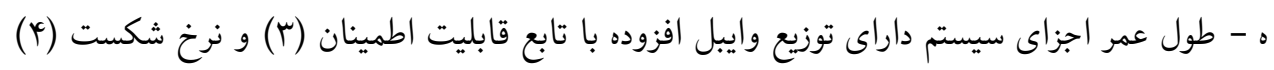

با بـتفاده از رابطه (1) مىتوان نشان داد، تابع قابليت اطمينان جنين سيستمى بعد از زمان t از انجام نكهدارى بيشكيرانه بهصورت

$$
R_{\text {sys }}(t)=\prod_{i=1}^{k}\left[1-\prod_{\ell=1}^{N} \prod_{j=1}^{n_{i}}\left(1-R_{\ell i j}(t)\right)^{X_{\ell i j}}\right]
$$

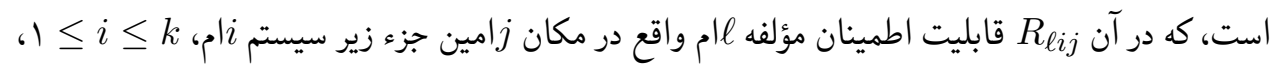

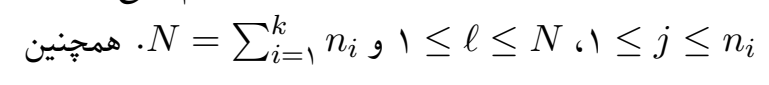

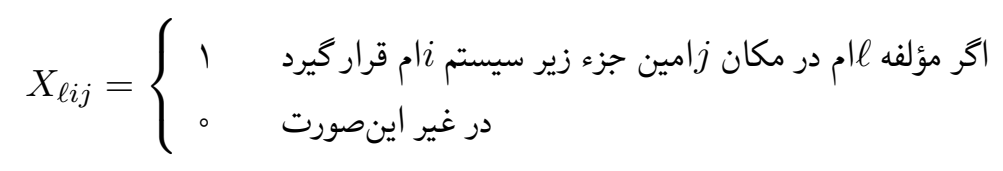

حال با استفاده از روابط (r) و (و) بدست مىآيد

$$
R_{s y s}(t)=\prod_{i=1}^{k}\left[1-\prod_{\ell=1}^{N} \prod_{j=1}^{n_{i}}\left\{1-\exp \left(-\left(a_{\ell i j} t\right)^{b_{\ell i j}}-\left(c_{\ell i j} t\right)^{d_{\ell i j}}\right)\right\}^{X_{\ell i j}}\right]
$$

كه در آن $1 \leq \ell \leq N$ ، $1 \leq j \leq n_{i} ، 1 \leq i \leq k$ إى

$$
. N=\sum_{i=1}^{k} n_{i} g
$$


معيار ديكر مورد مطالعه در اين مقاله تابع هزينه است كه از سه بخش هزينه مكانيابى اجزاى سيستم،

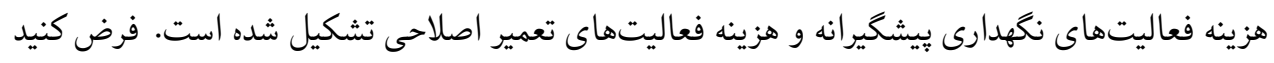
كأشان $C_{l i j}$ كل اجزاى سيستم به صورت

$$
C_{1}=\sum_{l=1}^{N} \sum_{i=1}^{k} \sum_{j=1}^{n_{i}} X_{\ell i j} C_{\ell i j}
$$

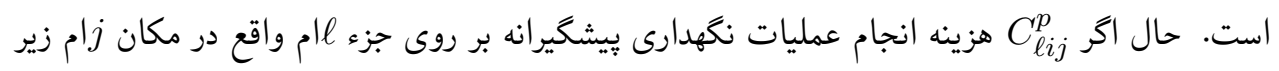

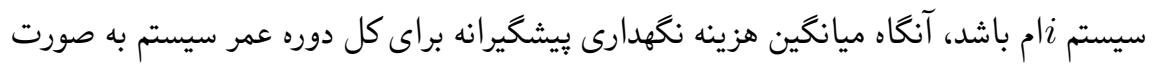

$$
\begin{aligned}
& C_{r}=\sum_{\ell=1}^{N} \sum_{i=1}^{k} \sum_{j=1}^{n_{i}} X_{\ell i j} C_{\ell i j}^{p}\left\lfloor\frac{T^{*}}{t}\right\rfloor, \\
& T^{*}= \begin{cases}t_{0} & 0<t<t \\
T-t_{0} & t_{\circ}<t<T\end{cases}
\end{aligned}
$$

كه در آن هt در رابطه (ه) تعريف شده است. اما با در نظر گرفتن يك دوره از نغهدارى بيشخيرانه تعداد

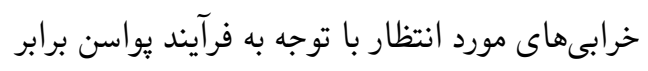

$$
E(N(t))=\int_{0}^{t} h(t) d t
$$

است، كه در آن (·) ابع نرخ شكست است. از رابطه (†) نتيجه مىشود

$E(N(t))=\int_{0}^{t} b_{\ell i j} a_{\ell i j}^{b_{\ell i j}} t^{b_{\ell i j}-1}+d_{\ell i j} c_{\ell i j}^{d_{\ell i j}} t^{d_{\ell i j}-1} d t=\left(t a_{\ell i j}\right)^{b_{\ell i j}}+\left(t c_{\ell i j}\right)^{d_{\ell i j}}$.

بنابراين در كل دوره عمر سيستم، تعداد خرابىهاى اتفاقى و در نتيجه تعداد تعميرات اصلاحى برابر 


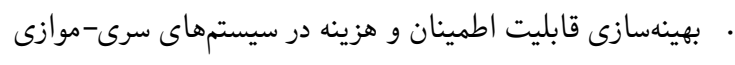

r9o

است. لذا با فرض اينكه $C_{\text {إن }}^{c}\left\{\left(t a_{\ell i j}\right)^{b_{\ell i j}}+\left(t c_{\ell i j}\right)^{d_{\ell i j}}\right\} \frac{T^{*}}{t}$

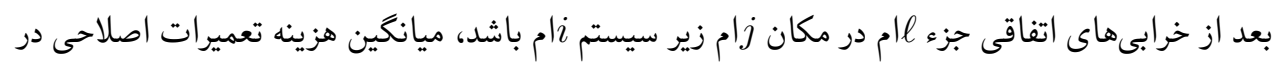

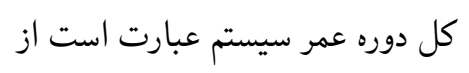
$C_{r}=\sum_{l=1}^{N} \sum_{i=1}^{k} \sum_{j=1}^{n_{i}}\left\{\left(t a_{\ell i j}\right)^{b_{\ell i j}}+\left(t c_{\ell i j}\right)^{d_{\ell i j}}\right\} X_{\ell i j} C_{\ell i j}^{c} \frac{T^{*}}{t}$.

با بكارگيرى روابط (^)، (9) و (11) تابع هزينه از رابطه

$$
\begin{aligned}
C_{\text {total }}= & C_{\uparrow}+C_{r}+C_{r} \\
= & \sum_{l=1}^{N} \sum_{i=1}^{k} \sum_{j=1}^{n_{i}} X_{\ell i j} C_{\ell i j}+\sum_{l=1}^{N} \sum_{i=1}^{k} \sum_{j=1}^{n_{i}} X_{\ell i j} C_{\ell i j}^{p}\left[\frac{T^{*}}{t}\right\rfloor \\
& +\sum_{l=1}^{N} \sum_{i=1}^{k} \sum_{j=1}^{n_{i}}\left\{\left(t a_{\ell i j}\right)^{b_{\ell i j}}+\left(t c_{\ell i j}\right)^{d_{\ell i j}}\right\} X_{\ell i j} C_{\ell i j}^{c} \frac{T^{*}}{t}
\end{aligned}
$$

محاسبه مىشود، كه در آن T $T^{*}$ در رابطه (10) تعريف شده است. از آنجا كه بيشينه كردن كمينه نمودن تابع

$$
\left\{\begin{array}{l}
\min 1-R_{\text {sys }} \\
\min C_{\text {total }}
\end{array}\right.
$$

$$
\begin{aligned}
& \text { محدوديتهاى مدل عبارتند از: }
\end{aligned}
$$

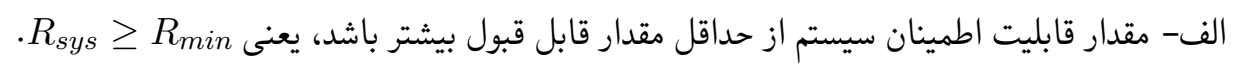

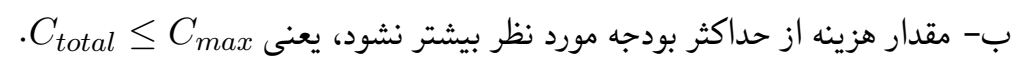

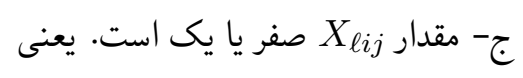

$$
\begin{aligned}
& X_{\ell i j}=\circ, 1, \quad \ell=1, \cdots, N, \quad N=\sum_{i=1}^{k} n_{i}, \quad j=1, \cdots, n_{i}, \quad i=1, \cdots, k \text {. }
\end{aligned}
$$




$$
\begin{gathered}
\text { د- هر جزء تنها در يك مكان قرار گيرد. به عبارتى در هر مكان تنها يك جزء قرار گيرد. به عبارتى } \sum_{i=1}^{k} \sum_{j=1}^{n_{i}} X_{\ell i j}=1, \quad \ell=1, \cdots, N, \quad N=\sum_{i=1}^{k} n_{i} . \\
\sum_{\ell=1}^{N} X_{\ell i j}=1, \quad \forall j=1, \cdots, n_{i}, \quad i=1, \cdots, k, \quad N=\sum_{i=1}^{k} n_{i} .
\end{gathered}
$$

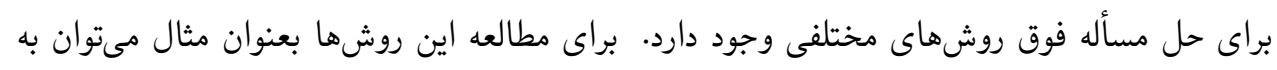

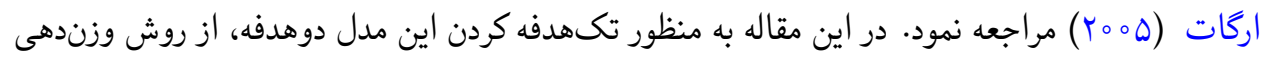

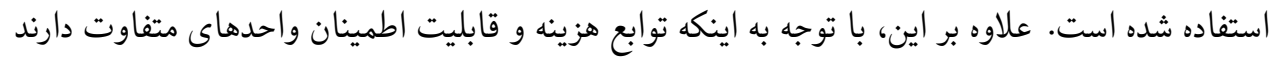

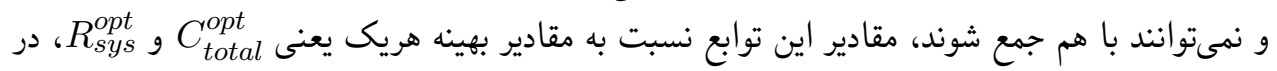

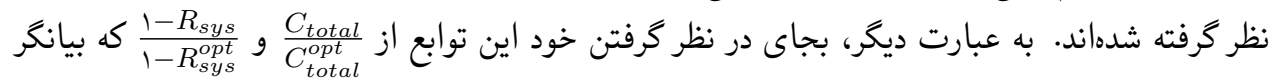

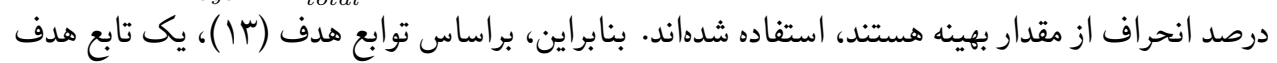
بهصورت

$$
W_{1} \frac{C_{t o t a l}}{C_{\text {total }}^{\text {ot }}}+W_{r} \frac{1-R_{\text {sys }}}{1-R_{\text {sys }}^{\text {opt }}}, \quad W_{1}+W_{r}=1, \circ \leq W_{1} \leq 1, \circ \leq W_{r} \leq 1 .
$$

در نظر گرفته مىشود كه بايد كمينه شود. از حل اين مسأله مقادير

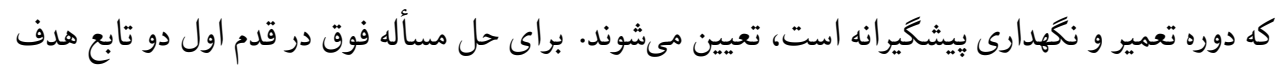

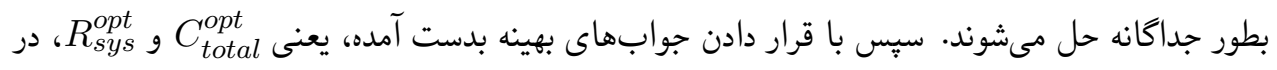
رابطه (1 (1) مدل جديد حل مىشود.

ملاحظه ا. اساساً مسائل بهينهازى جندهدفه داراى جواب منحصر بفرد نيستند. در /ينكونه مسائل

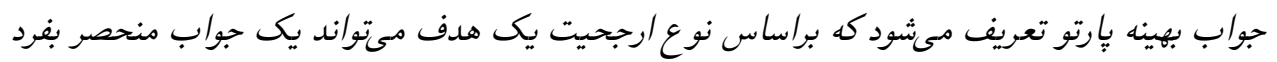

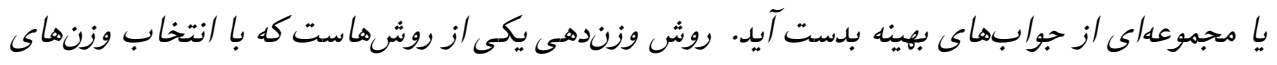

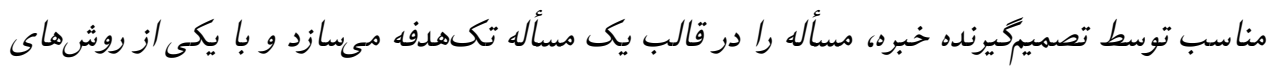

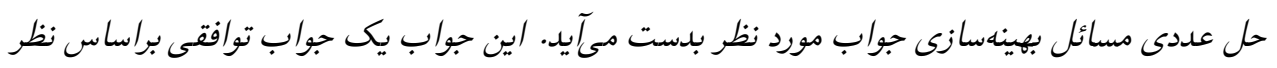


ملاحظه r. بعنوان حالت خاصى از سيستم سرى-موازى مىتوان سيستم سرى و سيستم موازى را در

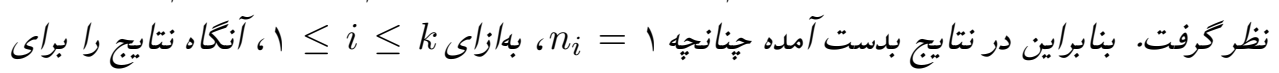

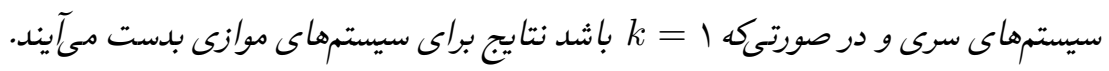

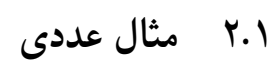

يك سيستم سرى-موازى بهصورت شكل ه ها در نظر بكيريد. فرض كنيد سه مؤلفه بايد در اين سيستم قرار

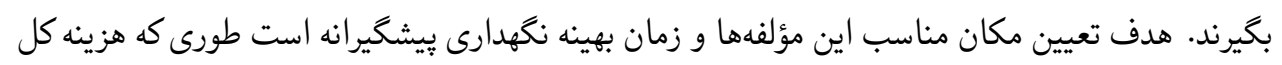
حداقل و قابليت اطمينان سيستم حداكثر شود.

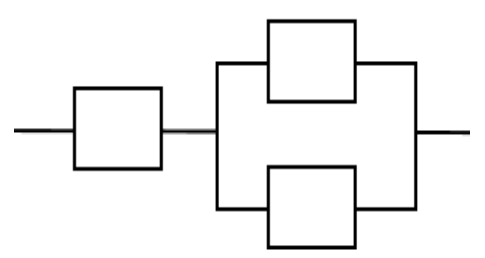

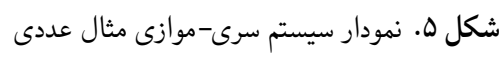

فرض كنيد هزينه استقرار جزء الام در مكان زام زير سيستم أم، هزينه انجام عمليات نكهدارى

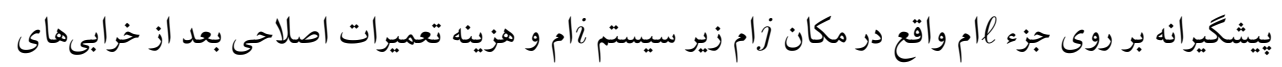

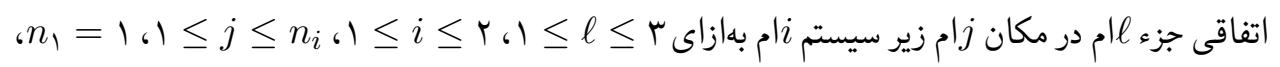

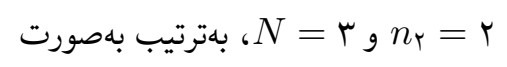

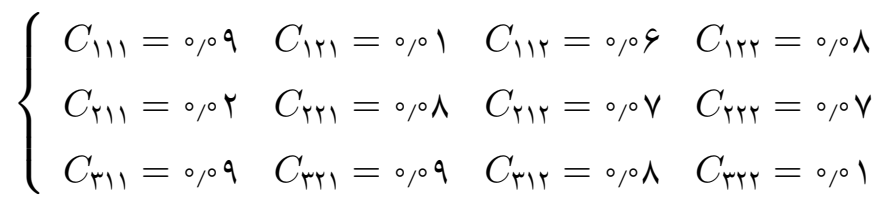

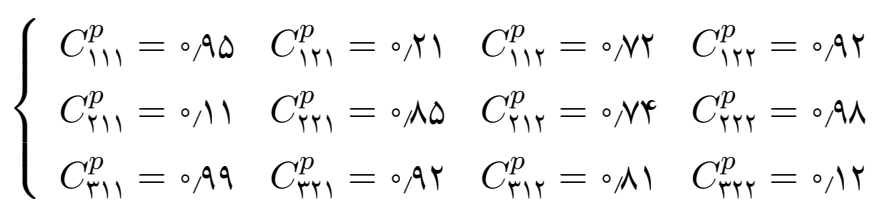




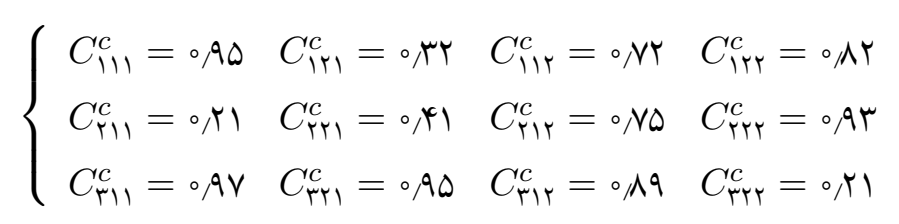

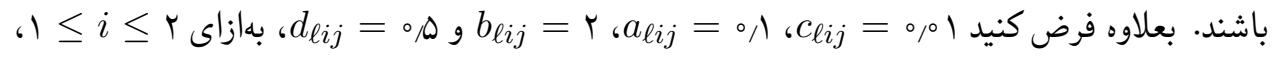

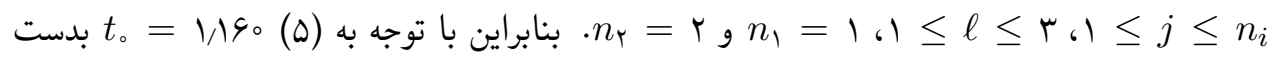
مىآيد. همجنين در اين مثال فرض مىشود r

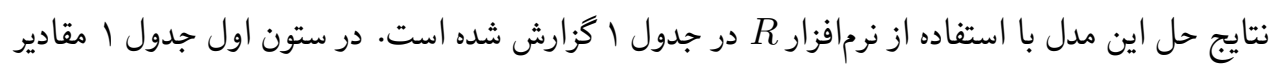

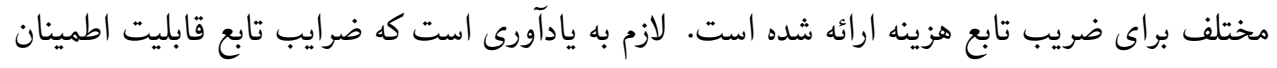
نيز از اين جدول قابل حصول است زيرا بـ

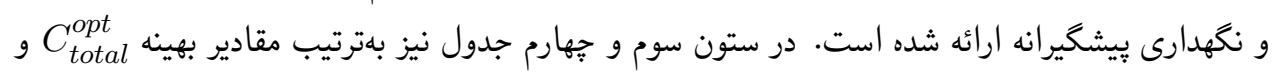

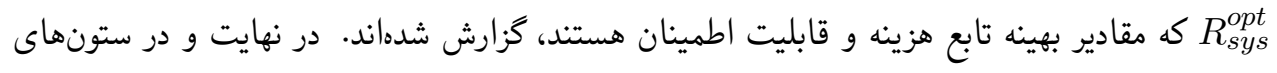

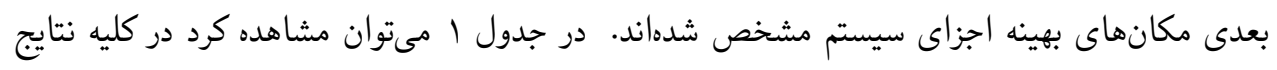
كسبشده

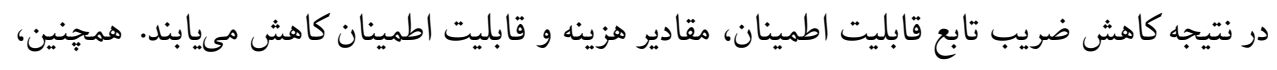

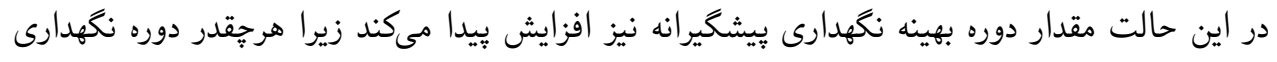

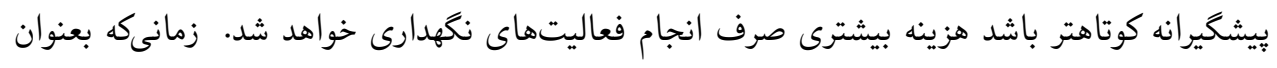

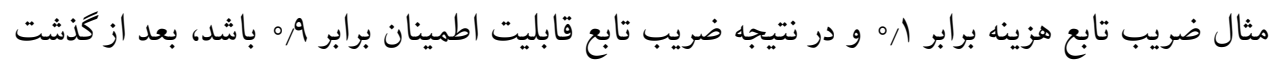

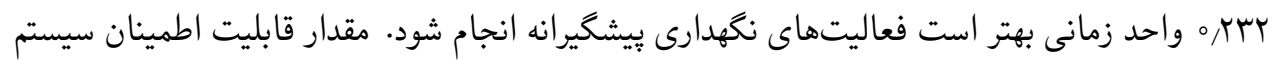

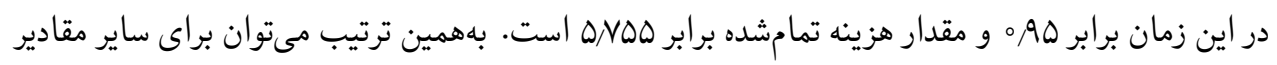

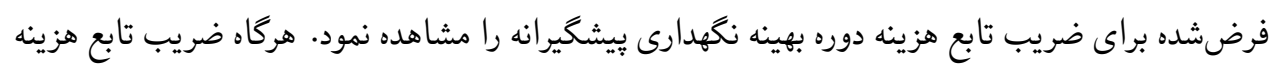

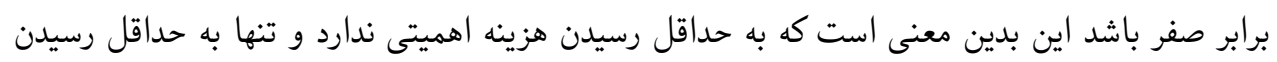
قابليت اطمينان تحت محدوديتهاى

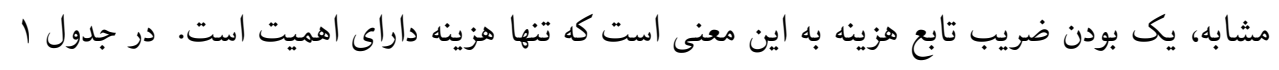

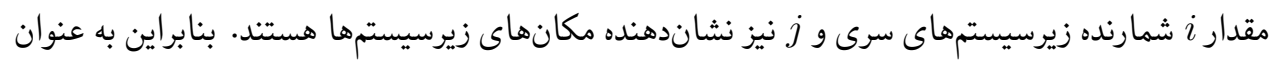

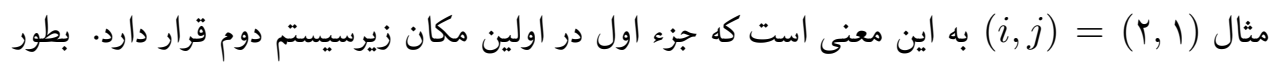

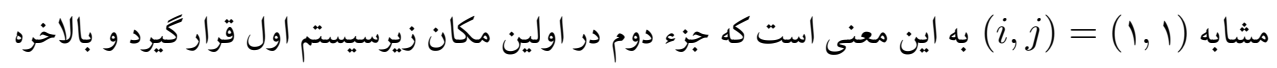




\begin{tabular}{|c|c|c|c|c|c|c|}
\hline \multicolumn{7}{|c|}{ 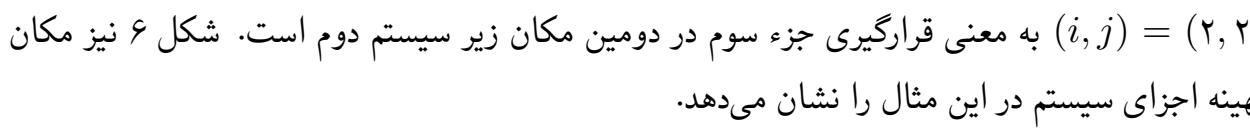 } \\
\hline \multicolumn{7}{|c|}{ جدول ا. نتايج حاصل از حل مدل در مثال عددى } \\
\hline & ل بينه اجزا & & & قالمقدار بهينه. & & \\
\hline 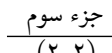 & 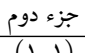 & جزءء اول & 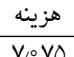 & قابليت اطمينان & ل دوره نكهدارى ييشكيرانه & ضريب تابع هزينه \\
\hline $\begin{array}{l}(r, Y) \\
(r, r)\end{array}$ & $\begin{array}{l}(1,1) \\
(1,1)\end{array}$ & $\begin{array}{l}(r, 1) \\
(r, 1)\end{array}$ & $\begin{array}{l}V_{\rho} \circ V_{\Delta} \\
\Delta, N \Delta \Delta\end{array}$ & $\begin{array}{l}0.900^{\circ} \\
0.900^{\circ}\end{array}$ & 年 & $\{0,1, \cdots, 0, \Delta\}$ \\
\hline$(r, r)$ & $(1,1)$ & $(r, 1)$ & $\Delta N \Delta \Delta$ & $\circ 900$ & 更 & $\{0,9, \circ, N\}$ \\
\hline$(r, r)$ & $(1,1)$ & $(r, 1)$ & re्र91 & o Aky & $0, \pi 90$ & $0 \wedge$ \\
\hline$(r, r)$ & $(1,1)$ & $(r, 1)$ & $1,9 \mathrm{Tr}$ & $\circ 900$ & r & $\{09,1\}$ \\
\hline
\end{tabular}

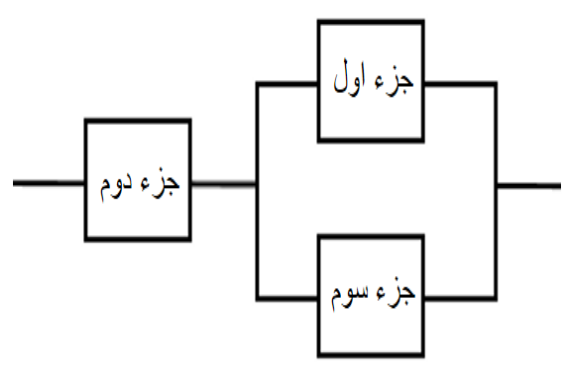

شكل 9. مكان بهينه اجزاى سيستم در مثال عددى

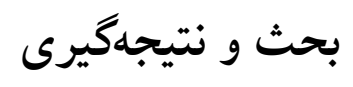

از آنجا كه دغدغه اكثر طراحان و كارفرمايان سيستهها افزايش قابليت اطمينان سيستم بدون افزايش

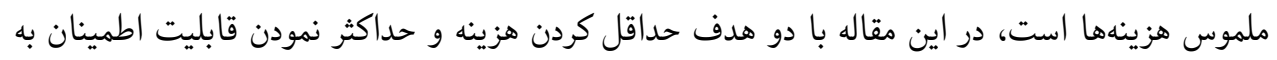

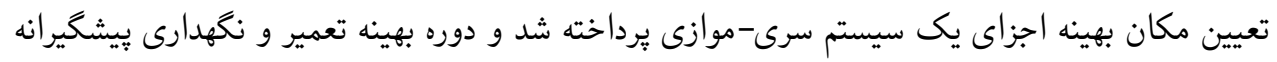

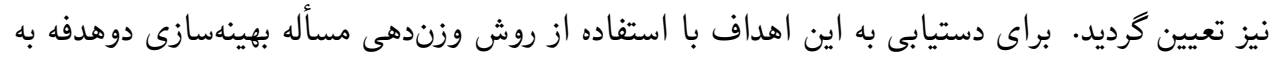

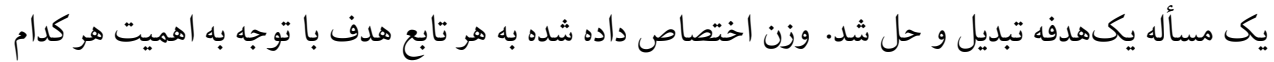

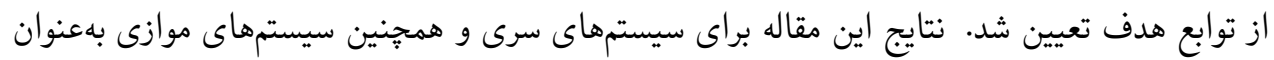
حالت خاصى قابل حصول است. 


\section{تقدير و تشكر}

لازم است از سردبير، هيئت تحريريه، داوران و ويراستار محترم مجله بهخاطر صرف وقت در مطالعه مقاله

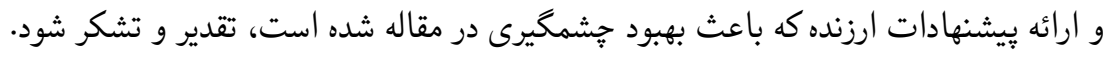

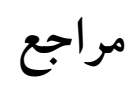

$$
\begin{aligned}
& \text { اسدى، م. (ه (1)). آشنايى با نظريه قابليت اعتماد، مركز نشر دانشخاهى، اصفهان، ويرايش دوم. } \\
& \text { ايرانمنش، ف.؛ رضايور، م. و بورموسى، ر. (ITYV) ). بهينهسازى تعمير و نكهدارى بيشخيرانه در يك سيستم }
\end{aligned}
$$

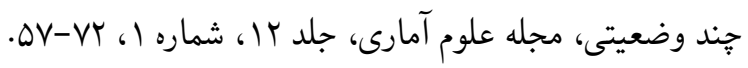

$$
\begin{aligned}
& \text { حاج شيرمحمدى، ع. (1901). برنامهريزى تعمير و نخهدارى، انتشارات اركان دانش، خاب بيستوسوم. }
\end{aligned}
$$

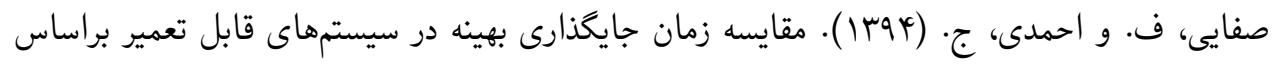

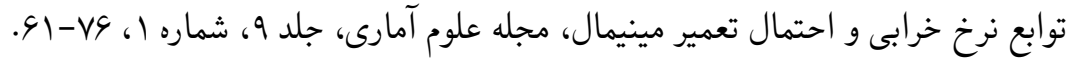

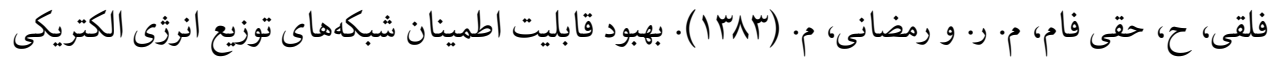

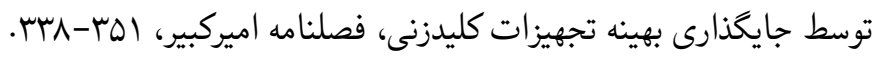

كرباسيان، م. و طباطبايى، ل. (1 ( ). آشنايى با قابليت اطمينان، انتشارات اركان دانش، اصفهان، جلد

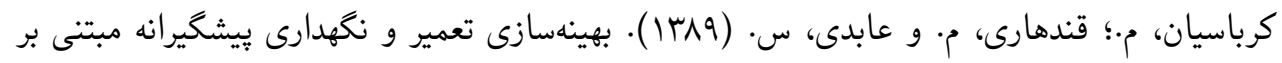

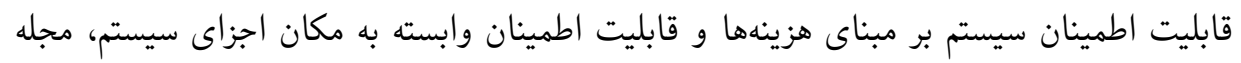

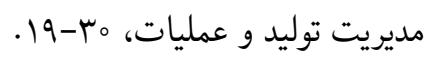

Ascher, H. and Feingold, H. (1984), Repairable Systems Reliability, New York:

M. Dekker.

Barlow, R. E. and Proschan, F. (1975), Statistical Theory of Reliability and Life Testing: Probability models, Florida State Univ Tallahassee. 
Bloom, N. (2005), Reliability Centered Maintenance (RCM): Implementation Made Simple, New York: McGraw-Hill.

Ehrgott, M. (2005), Multicriteria Optimization, (Vol. 491), Springer Science \& Business Media.

Lai, M. T. and Chen, Y. C. (2008), Optimal Replacement Period of a Twounit System with Failure Rate Interaction and External Shocks, International Journal of Systems Science, 39, 71-79.

Meeker, W. Q. and Escobar, L. A. (1998), Statistical Methods for Reliability Data, John Wiley and Sons. Inc., New York.

Salazar, D., Rocco, C. M. and Galván, B. J. (2006), Optimization of Constrained Multiple-Objective Reliability Problems Using Evolutionary Algorithms, Reliability Engineering and System Safety, 91, 1057-1070.

Taboada, H. A., Espiritu, J. F. and Coit, D. W. (2008), Design Allocation of Multistate Series-Parallel Systems for Power Systems Planning: A multiple Objective Evolutionary Approach, Proceedings of the Institution of Mechanical Engineers, Part O: Journal of Risk and Reliability, 222, 381391.

Wang, H. and Pham, H. (2006), Reliability and Optimal Maintenance, Springer Science and Business Media.

Xie, M. and Lai, C. D. (1996), Reliability Analysis Using an Additive Weibull Model with Bathtub-Shaped Failure Rate Function, Reliability Engineering and System Safety, 52, 87-93. 
Journal of Statistical Sciences, Spring and Summer, 2020

Vol. 14, No. 2, pp 351-366

DOI: $10.29252 /$ jss.14.2.351

\title{
Optimization of Reliability and Cost in Series-Parallel Re- pairable Systems with Bathtub-Shaped Failure Rate
}

\author{
E. Basiri \\ Department of Statistics, Kosar University of Bojnord, Bojnord , Iran.
}

\begin{abstract}
When a system is used, it is often of interest to determine with what probability it will work longer than a pre-fixed time. In other words, determining the reliability of this system is of interest. On the other hand, the reliability of each system depends on the structure and reliability of its components. Therefore, in order to improve the reliability of the system, the reliability of its components should be improved. For this purpose, it is necessary to carry out maintenance operations, which will increase costs. Another way to increase the reliability of systems is to change the location of the components. In this paper, the location of system components and optimal maintenance period are determined by minimizing the costs and maximizing the reliability of a series-parallel system. Finally, a numerical example is presented to evaluate the results in the paper.
\end{abstract}

Keywords: Series-Parallel System, Maintenance, Bathtub-Shaped Failure Rate, Optimization, Reliability.

Mathematics Subject Classification (2010): 62N05, 62P30. 